\title{
Over-the-scope clip as salvage therapy in refractory bleeding from esophageal variceal band ligation-induced ulcer
}

Endoscopic variceal band ligation (EVBL)induced ulcer bleeding is a known serious complication of banding, with a prevalence of $2.8 \%-15 \%$ and a mortality rate up to $52 \%[1-3]$. Treatment options are limited. Several modalities have been reported including EVBL, cyanoacrylate injection, argon plasma coagulation, Sengstaken-Blakemore tube, and hemostatic spray, with variable treatment success $[2,4]$. Herein, we present a case using an over-the-scope clip (OTSC) as salvage therapy in a patient with refractory bleeding from EVBL-induced ulcer despite standard endoscopic treatment. A 51-year-old man presented with esophageal variceal bleeding with hemorrhagic shock. He had a history of decompensated alcoholic cirrhosis (Child-Pugh Class B) and had undergone EVBL 3 weeks earlier for primary prophylaxis at an outside institution. Bleeding had persisted despite EVBL, selective angiogram with embolization, and transjugular intrahepatic portosystemic shunt. He was transferred to our hospital with an esophageal balloon tamponade tube. Upon arrival at our intensive care unit, the balloon tamponade tube was removed and upper endoscopy showed a large amount of blood clot in the esophagus, three columns of small esophageal varices, and multiple band ulcers from prior EVBL in the distal esophagus. There was a visible vessel at one of the band ulcers, which was thought to be the source of bleeding ( Fig. 1). A 12-mm OTSC (Ovesco Endoscopy AG, Tübingen, Germany) was mounted onto the gastroscope and deployed at the visible vessel, resulting in hemostasis ( $\vee$ Fig. 2, $\vee$ Video 1 ). He had no recurrent bleeding over a 4-month follow-up period.

In conclusion, OTSC for the management of recalcitrant EVBL-induced ulcer bleeding is effective and may be considered as salvage therapy for this fatal condition,

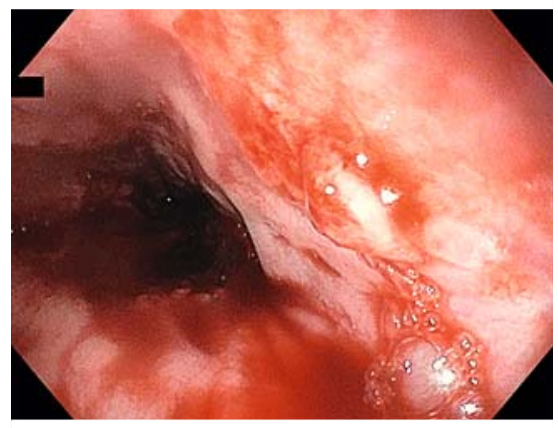

- Fig. 1 Upper endoscopy showed a visible vessel at the base of the band ulcer.

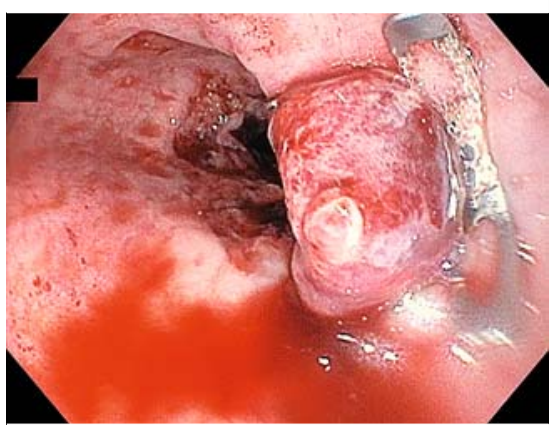

- Fig.2 Upper endoscopy showed successful deployment of an over-the-scope clip at the lesion to achieve hemostasis.

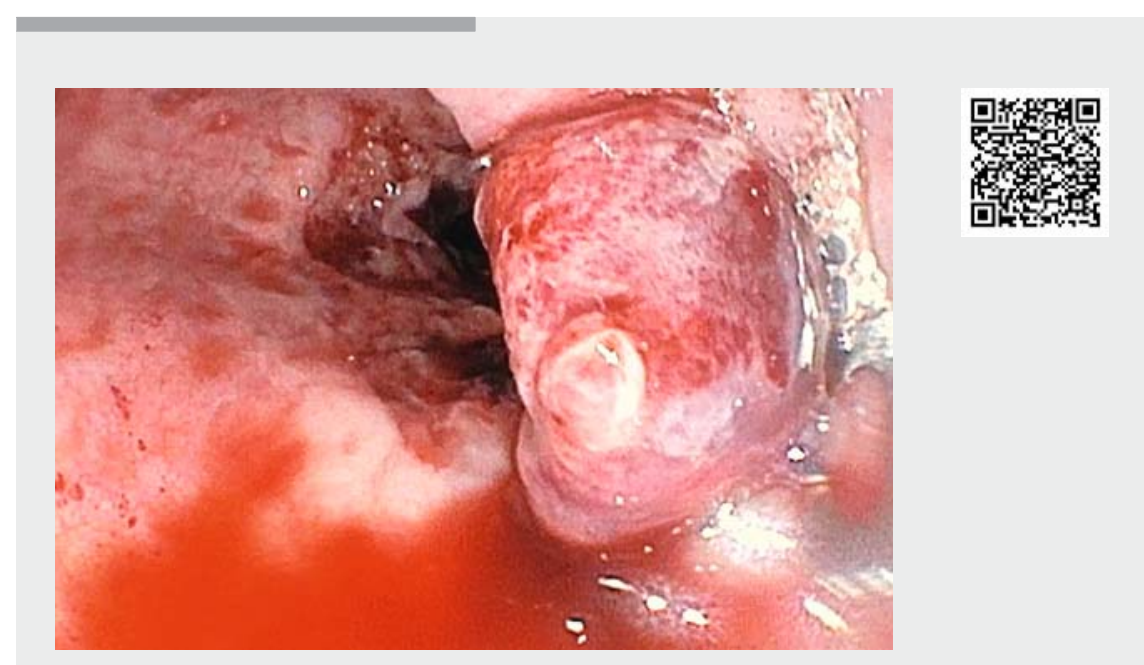

Video 1 Over-the-scope clip placement for refractory bleeding from esophageal variceal band ligation-induced ulcer.

especially in cases where a target source of bleeding can be identified, such as a visible vessel of the band ulcer.

Endoscopy_UCTN_Code_TTT_1AO_2AD

\section{Competing interests}

Dr. Ngamruengphong is a consultant for Boston Scientific.
The authors

Chawin Lopimpisuth, Tossapol Kerdsirichairat, Mirmilad Pourmousavi Khoshknab, James P. Hamilton, Saowanee Ngamruengphong

Division of Gastroenterology and Hepatology, Johns Hopkins University, Baltimore, Maryland, United States 


\section{Corresponding author}

\section{Saowanee Ngamruengphong, MD}

Division of Gastroenterology and

Hepatology, Johns Hopkins Medicine, 4940

Eastern Avenue, A Building, 5th Floor, A-501,

Baltimore, MD 21224, United States

Fax: +1-410-550-7861

sngamru1@jhmi.edu

\section{References}

[1] Sinclair M, Vaughan R, Angus PW et al. Risk factors for band-induced ulcer bleeding after prophylactic and therapeutic endoscopic variceal band ligation. Eur J Gastroenterol Hepatol 2015; 27: 928 - 932
[2] Cho E, Jun CH, Cho SB et al. Endoscopic variceal ligation-induced ulcer bleeding: what are the risk factors and treatment strategies? Medicine (Baltimore) 2017; 96: e7157

[3] Mishin I, Dolghii A. Early spontaneous slippage of rubber bands with fatal bleeding: a rare complication of endoscopic variceal ligation. Endoscopy 2005; 37: 275 - 276

[4] Wong Kee Song LM, Baron TH. Endoscopic management of procedure-related bleeding. Gastrointest Interv 2012; 1: 43-52

\section{Bibliography}

DOI https://doi.org/10.1055/a-0983-8230

Published online: 21.8.2019

Endoscopy 2020; 52: E33-E34

(c) Georg Thieme Verlag KG

Stuttgart · New York

ISSN 0013-726X

\section{ENDOSCOPY E-VIDEOS}

https:/|eref.thieme.de/e-videos

口㺼回 Endoscopy E-Videos is a free access online section, reporting 田: on interesting cases and new techniques in gastroenterological endoscopy. All papers include a high quality video and all contributions are freely accessible online.

This section has its own submission website at

https://mc.manuscriptcentral.com/e-videos 